
\title{
is Research Square \\ The suitability of glioblastoma cell lines as models for primary glioblastoma cell metabolism
}

Anya Lara Arthurs ( $\nabla$ anya.arthurs@flinders.edu.au )

Flinders University https://orcid.org/0000-0002-4382-0610

Damien J Keating

Flinders University

Simon J Conn

Flinders University

Research

Keywords: metabolism, glioblastoma multiforme, oncology, cell culture, metabolic flux

Posted Date: August 12th, 2020

DOI: https://doi.org/10.21203/rs.3.rs-56880/v1

License: () (i) This work is licensed under a Creative Commons Attribution 4.0 International License. Read Full License 


\section{Abstract \\ Background}

In contrast to most non-malignant cells, cells comprising Glioblastoma multiforme (GBM), a deadly brain tumour with extremely poor prognosis, preferentially utilise glycolysis over oxidative phosphorylation for metabolism in a phenomenon known as the 'Warburg effect'. As effective treatments for GBM are severely lacking, research into therapeutics targeting the disease's highly glycolytic state offer a promising avenue to improve patient survival. These studies often employ GBM cell lines for in vitro studies which translate poorly to the in vivo patient context.

\section{Methods}

The metabolic traits of the seven most commonly used GBM cell lines were assessed using a Seahorse Bioscience Metabolic Flux Analyser and compared to primary GBM cells and primary healthy mixed neural cells from the same patients.

\section{Results}

In support of the glycolytic nature of the patient-derived GBM cell lines, basal mitochondrial rate $(p=0.043)$ and ATP-linked respiration $(p<0.001)$ were significantly lower than primary adjacent normal cells from the same patient and reserve capacity $(p=0.037)$ and Krebs Cycle capacity $(p=0.002)$ were significantly higher for 12 patients. While no cell line was found to accurately replicate all metabolic attributes of primary GBM cells, specific parameters could be modelled by specific lines.

\section{Conclusions}

U251MG, U373MG and D54 lines are recommended for researching mitochondrial metabolism, and the D645 line for researching ATP-linked respiration. The T98G cell line recapitulated glycolysis-related metabolic parameters of the primary GBM cells and is recommended for research relating to glycolysis. These findings can guide preclinical research into the development of novel therapeutics targeting metabolic pathways in GBM.

\section{Background}

Glioblastoma multiforme (GBM) is an aggressive brain tumour with a poor survival rate (5-year survival rate < $10 \%$ ) which has improved only $1 \%$ in the past 30 years (1). Despite being the most common brain tumour in adults, successful therapies for GBM have not been found resulting in a median survival time of only 12-15 months, post-diagnosis (2). Within the last decade, research has turned to examining the therapeutic potential of drugs interrupting the metabolism of GBM cells, leading to slower proliferation rates and/or reduced metastasis (3). Like many cancers, GBM preferentially uses the less-efficient glycolytic pathway to produce energy in the form of ATP and NADH rather than the oxidative phosphorylation pathway favoured by most somatic cells. This shift in metabolic pathways is called "The Warburg Effect" and results in the accumulation of lactate regardless of oxygen availability (4). Dichloroacetate, which targets a key glycolytic pathway enzyme pyruvate 
dehydrogenase kinase $(5,6)$, has been demonstrated to inhibit tumour progression in vivo in lung and breast cancer $(5,7)$.

GBM tumours exhibit heterogeneity, both of the cells they comprise and the cellular metabolism profiles (8), which complicates their profiling. Often primary human GBM cells are unavailable, or instead xenografted in the murine brain to allow genetic manipulation in vivo (9). This can confound metabolic analyses compared with the primary tumour due to the effects from the tumour microenvironment (10). As a result, many researchers utilise established GBM cell lines as in vitro models. While different metabolic profiles have been completed for both primary GBM cells and GBM cell lines in vitro, there has been no comprehensive comparison. Furthermore, in vitro culturing conditions can have a large effect on cell growth (11-13) and thus, cellular metabolism.

This diversity in modelling the GBM disease presents a challenge, as research into potential GBM therapies which target metabolism may be confounded by which cell lines or models are used. To address this knowledge gap, we have compared the metabolic profiles of primary GBM cells (derived from GBM tumours) with primary healthy normal mixed neural cells from the same patients, as well as the seven most commonly used GBM cell lines: U87MG, U118MG, U251MG, U373MG, D645, D54 and T98G. This provided a reliable comparison of primary GBM cell metabolism with cell lines used for research, as well as with normal neural cells, to provide a clearer understanding of which GBM cell lines most closely represent primary GBM metabolism.

\section{Methods}

\section{Ethics}

For all primary tissue sourced for these experiments, written informed consent was obtained from each subject or from their guardian. Specimens were received from the SA Neurological Tumour Bank (SANTB) which is supported by Flinders University, Flinders Foundation and The Neurosurgical Research Foundation. The ethics for the SANTB is approved by the SAC HREC with approval number 286.10.

\section{Cell Line Culture}

GBM cell lines (U87MG, U118MG, U251MG, U373MG, D645, D54 and T98G), were obtained from ATCC and used at passages 6-8. Cells were cultured at $37^{\circ} \mathrm{C}$ with $5 \% \mathrm{CO}_{2}$ in air in DMEM (Sigma-Aldrich) supplemented with $10 \% \mathrm{v} / \mathrm{v}$ FBS (Sigma-Aldrich) and $1 \mathrm{mg} / \mathrm{mL}$ Antibiotic-Antimycotic (Sigma-Aldrich). Cells were plated at $5 \times 10^{4}$ cells per well in a Seahorse XFe 96 Cell Culture Microplate (Seahorse Bioscience, Agilent), $n=5$ per cell line with each sample plated in triplicate, before being left at room temperature (RT) for 1 hour to reduce the edge effect. Cells were then incubated $\left(24\right.$ hours, $37^{\circ} \mathrm{C}$ ) prior to analysis to facilitate cell attachment to the growth surface.

\section{Primary Brain Cell Culture}

Adult human brain tissue was collected at Flinders Medical Centre during neurosurgical resection of glioblastoma tumour. Healthy tissue adjacent to the tumour was obtained, as well as the glioblastoma tumour tissue. Each tissue type was collected at the time of resection and placed in $1 \mathrm{X}$ phosphate-buffered saline (PBS) solution, (pH $7.4,4^{\circ} \mathrm{C}$ ) and transported to the laboratory. The PBS solution was changed within 10 minutes of resection and the tube was gently inverted for 5 min to clean the tissue. 
Fat was removed and the tissue was cut into $2 \mathrm{~mm}^{3}$ pieces. The healthy tissue was transferred into a chelation buffer (3 mM ethylenediaminetetraacetic acid (EDTA), $50 \mu \mathrm{M}$ Dithiothreitol (DTT) in PBS) and the tumour tissue was transferred into Accumax ${ }^{\text {TM }}$ (Thermo-Fisher Scientific) and incubated at RT for $1 \mathrm{hr}$ (with gentle rocking). The tissue was then placed in PBS $\left(5 \mathrm{~mL}, 4^{\circ} \mathrm{C}\right)$ and vigorously agitated for 5 seconds. Supernatant was collected and this process was repeated until the supernatant remained clear after agitation. Collected supernatant was centrifuged (400 xg, $3 \mathrm{~min}, \mathrm{RT}$ ) and then supernatant was removed. The pellet was resuspended in $1.5 \mathrm{~mL}$ of icecold PBS before being passed through a cell sieve $(70 \mu \mathrm{m})$ to remove debris. Cells were then centrifuged again at $400 \mathrm{xg}$ for $1 \mathrm{~min}$ at room temperature before resuspension in $1 \mathrm{~mL}$ growth medium (as above) and cells were counted using a hemocytometer and filtered trypan blue (1\%; Sigma Aldrich) to exclude dead cells. Cells were then plated at $5 \times 10^{4}$ cells per well in a Seahorse XF ${ }^{e} 96$ Cell Culture Microplate (Seahorse Bioscience, Agilent), in triplicate wells for $n=13$ tumours, $n=8$ normal, before being left at RT for 1 hour to minimise edging. Cells were then moved into the $37^{\circ} \mathrm{C}$ incubator for 2 hours further to allow for adhesion.

To maintain a mixed population of neural cells (including astrocytes, oligodendrocytes and neurons), cells were grown in a media containing serum for only 3 hours. This time frame was chosen as it is not long enough to significantly diminish neuron growth whilst also encouraging astrocyte growth which is retarded in serum-free media $(14,15)$.

\section{Metabolic Flux Analysis}

To assess flux through cytoplasmic and mitochondrial metabolic pathways, cells were assayed using a Seahorse Bioscience XF Analyser and Mitostress test kit according to manufacturer's instructions (Agilent Technologies User Guide Kit 103015-100).

When the assays were complete, plates were fixed with $4 \%$ paraformaldehyde before imaging (Cytation 5) with high-resolution brightfield. This calculated the number of cells per well which was used for normalisation between wells in each plate.

\section{Metabolic Capacity Calculations}

Oxygen Consumption Rate (OCR) was used for calculation of mitochondrial and related metabolic parameters of the cells tested (Fig. 1). Non-mitochondrial respiration was assessed based on OCR after Rotenone/Antimycin A injection. Basal mitochondrial rate was calculated as OCR at baseline, minus non-mitochondrial respiration rate. Proton leak was calculated as OCR after oligomycin injection, minus non-mitochondrial respiration rate. ATPlinked respiration was calculated as baseline OCR, minus OCR after oligomycin injection. Reserve capacity was calculated as OCR after injection with FCCP, minus baseline OCR. Finally, maximal mitochondrial respiration was calculated as OCR after FCCP injection, minus non-mitochondrial respiration.

Extracellular Acidification Rate (ECAR) of cells was used for calculation of glycolytic metabolic parameters (Fig. 2). Basal glycolysis was based on ECAR at baseline. Glycolytic capacity was calculated as ECAR after oligomycin injection, minus basal ECAR. Krebs Cycle capacity was calculated as ECAR after FCCP injection, minus glycolytic capacity.

\section{Statistics}


Statistical analysis was undertaken using Prism 7 (GraphPad). Data was assessed for normality distribution and a one-way ANOVA (non-parametric) test was conducted using a Kruskal-Wallis multiple comparisons test.

Differences between groups were considered significant for $p \leq 0.05$. All tests of statistical significance are twosided.

\section{Results}

Baseline Oxygen Consumption Rate (OCR) comparison of primary healthy and GBM cells, and GBM cell lines

Baseline OCR was measured to determine the normal mitochondrial respiration of different cells and cell lines. No significant variation was observed specific to patient sex or nationality. Primary healthy mixed neural cells exhibited significantly higher OCR (27\%) compared to primary GBM cells from the same patient $(p<0.001)$ (Fig. 3). Furthermore, U118MG ( $p<0.001)$, U373MG $(p<0.001)$, D645 $(p=0.002)$ and T98G $(p<0.001)$ displayed significantly higher baseline OCR compared with only the primary GBM tumour control. U87MG and U251MG were only significantly decreased compared with the primary healthy control $\left(p_{U 87 M G}<0.001, p_{U 251 M G}=0.011\right)$. This indicates that most cell lines display different mitochondrial metabolism in culture compared with primary resected tissue.

\section{Comparison of mitochondrial function in response to metabolism-altering compounds}

Oligomycin inhibits the proton channel of ATP synthase in cells, hindering their ability to produce ATP and consume oxygen via mitochondrial oxidative phosphorylation (16). As such, OCR is expected to decrease upon exposure to this compound. All cells responded in this manner, showing significantly reduced OCR when treated with oligomycin $\left(p_{\text {healthy }}=0.027 ; p_{1^{\prime} G B M}=0.048 ; p_{U 87 M G}=0.004 ; p_{U 118 M G}<0.001 ; p_{U 251 M G}=0.007 ; p_{U 373 M G}<0.001\right.$; $\left.p_{D 645}=0.003 ; p_{D 54}=0.029 ; p_{T 98 G}=0.002\right)$ when compared with their respective baselines (Fig. 4). Treatment with the protonophore FCCP, a potent uncoupler of mitochondrial oxidative phosphorylation, disrupts ATP synthesis by interfering with the proton gradient generated by the electron transport chain before it can be utilised for energy. A significant increase in OCR is expected following administration of this compound. Healthy cells $(p=0.044)$, U87MG ( $p=0.042)$, D54 ( $p=0.024)$ and T98G $(p=0.019)$ cells showed significantly increased OCR following FCCP administration when compared with their respective baselines, with the remaining lines being unaffected.

Finally, a mix of rotenone and antimycin A are added, which inhibit mitochondrial electron transport complexes I and III, respectively. This is expected to significantly decrease the OCR of cells. All cells had significantly reduced OCR when treated with rotenone/antimycin A $\left(p_{\text {healthy }}<0.001 ; p_{1^{\prime} G B M}<0.001 ; p_{U 87 M G}<0.001 ; p_{U 118 M G}<0.001\right.$;

$\left.p_{U 251 M G}<0.001 ; p_{U 373 M G}<0.001 ; p_{D 54}<0.001\right)$ when compared with their respective baselines, excepting D645 and T98G cell lines which were unaffected.

\section{Metabolic parameters pertaining to OCR and ECAR}

The addition of metabolism-altering compounds oligomycin, FCCP and rotenone/antimycin A allows for calculation of metabolic parameters pertaining to the OCR and ECAR of the cells. Table 1 and Fig. 5 display the statistical and diagrammatic results, respectively, of metabolic parameters pertaining to OCR. 
Table 1

- Values of significance for cell comparisons of OCR-related metabolic parameters

\begin{tabular}{|c|c|c|c|c|c|c|c|c|c|}
\hline Parameter & Healthy & $\begin{array}{l}1^{\prime} \\
\text { GBM }\end{array}$ & U87MG & U118MG & U251MG & U373MG & D645 & D54 & T98G \\
\hline $\begin{array}{l}\text { Non-mito } \\
\text { respiration }\end{array}$ & & & $\begin{array}{l}p= \\
0.007\end{array}$ & $\begin{array}{l}p= \\
0.022\end{array}$ & & & & $\begin{array}{l}p< \\
0.001\end{array}$ & $\begin{array}{l}p= \\
0.012\end{array}$ \\
\hline $\begin{array}{l}\text { Basal } \\
\text { mito rate }\end{array}$ & & $\begin{array}{l}p= \\
0.043\end{array}$ & $\begin{array}{l}p< \\
0.001\end{array}$ & & $\begin{array}{l}p= \\
0.003\end{array}$ & & $\begin{array}{l}p< \\
0.001\end{array}$ & & $\begin{array}{l}p< \\
0.001\end{array}$ \\
\hline $\begin{array}{l}\text { ATP-linked } \\
\text { resp rate }\end{array}$ & & $\begin{array}{l}p< \\
0.001\end{array}$ & & & & & $\begin{array}{l}p= \\
0.011\end{array}$ & & \\
\hline $\begin{array}{l}\text { Proton } \\
\text { leak }\end{array}$ & & & $\begin{array}{l}p= \\
0.006\end{array}$ & $\begin{array}{l}p= \\
0.031\end{array}$ & & & $\begin{array}{l}p= \\
0.009\end{array}$ & & $\begin{array}{l}p= \\
0.006\end{array}$ \\
\hline $\begin{array}{l}\text { Reserve } \\
\text { capacity }\end{array}$ & & $\begin{array}{l}p= \\
0.037\end{array}$ & & $\begin{array}{l}p< \\
0.001\end{array}$ & & & $\begin{array}{l}p= \\
0.001\end{array}$ & & \\
\hline $\begin{array}{l}\text { Maximal } \\
\text { resp rate }\end{array}$ & & & & & & & $\begin{array}{l}p< \\
0.001\end{array}$ & & $\begin{array}{l}p< \\
0.001\end{array}$ \\
\hline $\begin{array}{l}\text { Non-mito } \\
\text { respiration }\end{array}$ & & & $\begin{array}{l}p= \\
0.004\end{array}$ & & & & & $\begin{array}{l}p= \\
0.002\end{array}$ & $\begin{array}{l}p= \\
0.007\end{array}$ \\
\hline $\begin{array}{l}\text { Basal } \\
\text { mito rate }\end{array}$ & $\begin{array}{l}p= \\
0.043\end{array}$ & & $\begin{array}{l}p= \\
0.002\end{array}$ & & & & $\begin{array}{l}p= \\
0.004\end{array}$ & & $\begin{array}{l}p= \\
0.020\end{array}$ \\
\hline $\begin{array}{l}\text { ATP-linked } \\
\text { resp rate }\end{array}$ & $\begin{array}{l}p< \\
0.001\end{array}$ & & $\begin{array}{l}p= \\
0.004\end{array}$ & $\begin{array}{l}p< \\
0.001\end{array}$ & $\begin{array}{l}p= \\
0.004\end{array}$ & $\begin{array}{l}p< \\
0.001\end{array}$ & & $\begin{array}{l}p< \\
0.001\end{array}$ & $\begin{array}{l}p< \\
0.001\end{array}$ \\
\hline $\begin{array}{l}\text { Proton } \\
\text { leak }\end{array}$ & & & $\begin{array}{l}p= \\
0.011\end{array}$ & & & & $\begin{array}{l}p= \\
0.015\end{array}$ & & $\begin{array}{l}p= \\
0.011\end{array}$ \\
\hline $\begin{array}{l}\text { Reserve } \\
\text { capacity }\end{array}$ & $\begin{array}{l}p= \\
0.037\end{array}$ & & & $\begin{array}{l}p< \\
0.001\end{array}$ & $\begin{array}{l}p< \\
0.001\end{array}$ & $\begin{array}{l}p< \\
0.001\end{array}$ & $\begin{array}{l}p< \\
0.001\end{array}$ & & $\begin{array}{l}p< \\
0.001\end{array}$ \\
\hline $\begin{array}{l}\text { Maximal } \\
\text { resp rate }\end{array}$ & & & & $\begin{array}{l}p= \\
0.012\end{array}$ & & & $\begin{array}{l}p< \\
0.001\end{array}$ & & $\begin{array}{l}p< \\
0.001\end{array}$ \\
\hline
\end{tabular}

Non-mitochondrial respiration records the consumption of oxygen occurring in alternative locations of the cell to the mitochondrion, such as at the cell-surface via transplasma membrane electron transport, or by cytosolic enzymes such as NADPH oxidase (17).

Basal mitochondrial rate provides a representation of the baseline mitochondrial respiration of the cells in standard assay conditions.

The ATP-linked respiration rate (oxygen consumption driven by ATP synthesis in mitochondria) provides a representation of several parameters, including ATP demand or substrate supply and oxidation in the cell.

Mitochondrial proton leak describes the diffusion of protons across the inner membrane independently of ATPsynthase, and results in continued mitochondrial oxygen consumption in the presence of oligomycin. Proton leak can be affected by several factors including the uncoupling protein family or mitochondrial membrane damage. 
The reserve capacity rate, or spare respiratory capacity, provides a representation of the cell's ability to meet increased energy demands and changes can reflect alterations in mitochondrial biogenesis/mass or altered arrangement of oxidative phosphorylation components on the inner mitochondrial membrane.

The maximal respiration rate provides a representation of the greatest amount of respiration the cell can provide whilst FCCP uncouples the proton gradient in the electron transport chain. This measurement relies on several parameters, including mitochondrial biogenesis or substrate supply and oxygen transport/metabolism in the cell.

Glycolysis is determined through measurements of the ECAR of the surrounding media, which is predominantly from the excretion of lactic acid after its conversion from pyruvate (16). Table 2 and Fig. 6 display the statistical and diagrammatic results, respectively, of metabolic parameters pertaining to ECAR.

Table 2

Values of significance for cell comparisons of ECAR-related metabolic parameters

\begin{tabular}{|c|c|c|c|c|c|c|c|c|c|}
\hline Parameter & Healthy & $\begin{array}{l}1^{\prime} \\
\text { GBM }\end{array}$ & U87MG & U118MG & U251MG & U373MG & D645 & D54 & T98G \\
\hline $\begin{array}{l}\text { Basal } \\
\text { glycolysis }\end{array}$ & & & $\begin{array}{l}p= \\
0.006\end{array}$ & $\begin{array}{l}p= \\
0.009\end{array}$ & $\begin{array}{l}p= \\
0.006\end{array}$ & $\begin{array}{l}p= \\
0.009\end{array}$ & $\begin{array}{l}p= \\
0.009\end{array}$ & $\begin{array}{l}p= \\
0.009\end{array}$ & \\
\hline $\begin{array}{l}\text { Glycolytic } \\
\text { capacity }\end{array}$ & & & $\begin{array}{l}p= \\
0.038\end{array}$ & $\begin{array}{l}p< \\
0.001\end{array}$ & & $\begin{array}{l}p< \\
0.001\end{array}$ & $\begin{array}{l}p< \\
0.001\end{array}$ & $\begin{array}{l}p< \\
0.001\end{array}$ & \\
\hline $\begin{array}{l}\text { Krebs } \\
\text { Cycle } \\
\text { Capacity }\end{array}$ & & $\begin{array}{l}p= \\
0.002\end{array}$ & & & $\begin{array}{l}p= \\
0.002\end{array}$ & & $\begin{array}{l}p= \\
0.004\end{array}$ & & \\
\hline $\begin{array}{l}\text { Basal } \\
\text { glycolysis }\end{array}$ & & & $\begin{array}{l}p= \\
0.004\end{array}$ & $\begin{array}{l}p< \\
0.001\end{array}$ & $\begin{array}{l}p< \\
0.001\end{array}$ & $\begin{array}{l}p= \\
0.025\end{array}$ & $\begin{array}{l}p= \\
0.034\end{array}$ & $\begin{array}{l}p< \\
0.001\end{array}$ & \\
\hline $\begin{array}{l}\text { Glycolytic } \\
\text { capacity }\end{array}$ & & & $\begin{array}{l}p= \\
0.035\end{array}$ & $\begin{array}{l}p< \\
0.001\end{array}$ & & $\begin{array}{l}p< \\
0.001\end{array}$ & $\begin{array}{l}p< \\
0.001\end{array}$ & $\begin{array}{l}p< \\
0.001\end{array}$ & \\
\hline $\begin{array}{l}\text { Krebs } \\
\text { Cycle } \\
\text { Capacity }\end{array}$ & $\begin{array}{l}p= \\
0.002\end{array}$ & & $\begin{array}{l}p= \\
0.005\end{array}$ & $\begin{array}{l}p= \\
0.003\end{array}$ & $\begin{array}{l}p< \\
0.001\end{array}$ & $\begin{array}{l}p= \\
0.001\end{array}$ & $\begin{array}{l}p< \\
0.001\end{array}$ & $\begin{array}{l}p< \\
0.001\end{array}$ & \\
\hline
\end{tabular}

Oligomycin inhibits the proton channel of ATP synthase in cells, hindering their ability to produce ATP via mitochondrial oxidative phosphorylation, requiring cells to increase glycolytic flux as a compensatory mechanism to meet cellular ATP demands (16). Thus, the ECAR following oligomycin treatment provides an indication of the maximal glycolytic capacity of the cell population of interest.

FCCP has been shown to often increase ECAR in cells. This increase is primarily caused by increased $\mathrm{CO}_{2}$ production from the Krebs cycle, upregulated to meet demand for $\mathrm{NADH}$ and $\mathrm{FADH}_{2}$ from the electron transport chain (ETC). $\mathrm{CO}_{2}$ converts to bicarbonate and protons in aqueous environment, thus contributing to extracellular acidification (16). The measurement of ECAR difference from FCCP treatment to oligomycin treatment is taken as a measure of $\mathrm{CO}_{2}$ production and acidification of the medium. As oligomycin almost entirely inhibits mitochondrial oxygen consumption, Krebs cycle activity is likely stalled, as cofactors $\mathrm{NADH} / \mathrm{FADH} \mathrm{H}_{2}$ are no longer required for the ETC. This measurement is therefore largely reflective of glycolysis/glycolytic flux. When FCCP treatment is added, maximal rate of ETC is initiated and the cell ineffectually attempts to reinstate mitochondrial proton gradient (which is then dissipated by FCCP). However, this sudden maximal ETC activity requires 
cofactors $\mathrm{NADH} / \mathrm{FADH}_{2}$ as electron donors and Krebs cycle activity is increased to meet the high demand. In addition to these products, Krebs cycle also produces an amount of $\mathrm{CO}_{2}$, thus acidifying its' aqueous medium environment.

\section{Discussion}

We have shown that a panel of the most widely used GBM model cell lines fail to faithfully recapitulate the metabolic activity of primary GBM tumours. Furthermore, we have specifically identified several metabolic parameters in which primary GBM cells differ from primary healthy mixed neural cell populations, as well as those parameters which are best mirrored in GBM cell lines. Importantly, the commonly used GBM cell lines showed no difference in baseline glycolysis from primary healthy cells, although they had different basal OCRs, reaffirming the need to target the correct cell lines for bespoke research projects.

Metabolism in the brain relies on an interaction between neurons and astrocytes. Glycogen is predominantly found in astrocytes (18) which contain enzymes to activate high levels of glycolytic metabolism, mainly releasing lactate $(19,20)$. Lactate and pyruvate transfer can occur to localised neurons $(21)$, where this enters the Krebs cycle and can continue through the oxidative phosphorylation pathway. Thus, an interplay between astrocytes and neurons is required for successful metabolic activity, underscoring our choice of a mixed neural cell population for our primary healthy cells.

Some metabolic parameters of cell activity were found to be similar between primary healthy and GBM cells. As summarised in Table 3, primary healthy and GBM cells were not statistically different in their non-mitochondrial respiration rates or maximal mitochondrial respiration rates, nor were they different in their basal ECAR or ECAR after oligomycin. As such, these parameters may be poor therapeutic targets, given that healthy cells display similar attributes to tumour cells. However, many metabolic parameters were statistically different between primary healthy and GBM cells that could illuminate the most promising targets for novel therapeutics (Table 3).

The addition of FCCP to primary GBM cells (Fig. 3B) did not elicit an increase in OCR, indicating a loss of reserve capacity. This was also seen in the majority of GBM cell lines (U118MG, U251MG, U373MG, D645 and T98G). One explanation for this is that tumour cells are known to predominantly utilise "The Warburg Effect", reducing their reliance on mitochondrial respiration (4). Thus, administration of an uncoupling agent may result in a lesser increase in oxygen consumption as the activity of the electron transport chain is already reduced. To support this hypothesis, both the baseline OCR (Fig. 3) and the basal mitochondrial rate (Fig. 5B) of primary GBM cells were observed as significantly lower than that of primary healthy cells.

Studies often utilise GBM cell lines for metabolic research, due to their relative accessibility and propagation potential. The issue that GBM cell lines differ in their metabolic activity from primary disease cells has been previously examined, yet no previous study has incorporated this number of commonly used GBM cell lines for more comprehensive metabolic profiling. Separate tumour cell lines have been found to respond differently to metabolism-altering compounds, with some eliciting heightened responses, due to their endogenous levels of hypoxia-induced factor 1-alpha (22). The PTEN status of cell lines has been shown to affect metabolic activity (23) as well as p53 (24). Potentially due to their mutant p53 alleles (25), the primarily glycolytic lines U251 and T98G have been shown to be unable to properly activate AMPK signalling (26) which is critical for survival in a hypoxic environment (27). In our study, we observed no change in response to rotenone/antimycin A after FCCP 
administration in D645 and T98G cells, potentially due to similar genomic modifications which may be revealed in further study.

The data presented in this study is useful for the recommendation of cell lines to be used as GBM models in metabolic studies. No single cell line appears to reflect the metabolic activity of primary GBM cells completely (Table 3), although it can be deduced that U87MG and T98G cell lines may be poor models for mitochondrial metabolism. D645 is the only line which accurately reflected the ATP-linked respiration of primary GBM cells, although most other metabolic attributes were not correctly portrayed in the cell line. Therefore, cell lines U251MG, U373MG and D54 cells would be most accurate for modelling the mitochondrial metabolism of primary GBM cells, with D54 cells being the preferred choice for studies researching reserve capacity. T98G clearly would be the optimal model for glycolysis-related metabolic research, mirroring all measured attributes of primary GBM cells.

There are limitations to this study which must be noted. While several GBM cell lines were examined in this study, this list was not exhaustive. Also, this study utilised the Mito Stress Kit (Seahorse Bioscience) for assessing metabolic parameters, which provided a broad assessment of cellular metabolic activity. Further study into the specifics of glycolytic metabolism, fatty acid oxidation and pentose phosphate pathway metabolism could be illuminated using blocking drugs such as 2-DG or 6-aminonicotinamide; these were beyond the scope of this study.

\section{Conclusion}

Whenever possible, primary human GBM cells should be sourced for metabolism studies as they will provide the most accurate representation of metabolic responses. However, GBM cell lines can be useful substitutes for measuring specific metabolic responses and therapeutics targeting specific components of these pathways. We recommend the use of U251MG, U373MG and D54 cells for mitochondrial metabolism studies, and T98G cells for glycolysis metabolism studies.

\section{Declarations}

\section{Ethics approval:}

Ethics approval was provided by the SAC HREC as described in Methods.

\section{Consent for publication:}

Not applicable.

\section{Availability of data and materials:}

All data generated or analysed during this study are included in this published article.

\section{Competing interests:}

The authors have no conflict of interest to declare. 


\section{Funding:}

This work was supported by a National Health and Medical Research Council project grant awarded to S.J.C. (GNT1144250).

\section{Author Contributions:}

A.L.A. was involved in the original concept for the study, completed all experiments, analysed the data and wrote the manuscript. D.J.K. made substantial contributions data analysis and manuscript editing. S.J.C. was involved in the original concept and made substantial contributions to manuscript editing.

\section{Acknowledgements:}

We would like to acknowledge the SANTB for providing the tissue used for this work.

\section{Abbreviations}

GBM Glioblastoma Multiforme

ATP Adenosine Triphosphate

NADH Nicotinamide Adenine Dinucleotide

SANTB South Australian Neurological Tumour Bank

SAC HREC Southern Adelaide Clinical Human Research Ethics Committee

DMEM Dulbecco's Modified Eagle Medium

FBS Fetal Bovine Serum

RT Room Temperature

PBS Phosphate-Buffered Saline

EDTA Ethylenediaminetetraacetic acid

DTT Dithiothreitol

OCR Oxygen Consumption Rate

FCCP Carbonyl Cyanide-p-trifluoromethoxyphenylhydrazone

ECAR Extracellular Acidification Rate

$\mathrm{FADH}_{2}$ Flavin Adenine Dinucleotide

$\mathrm{CO}_{2}$ Carbon Dioxide 
ETC Electron Transport Chain

PTEN Phosphatase and Tensin Homolog

AMPK Adenosine Monophosphate-activated Protein Kinase

\section{References}

1. AlHW C. Cancer in Australia. 2017.

2. Stupp R MW, van den Bent MJ, Weller M, Fisher B, Taphoorn MJ, et al. Radiotherapy plus concomitant and adjuvant temozolomide for glioblastoma. N Engl J Med. 2005;352:987-96.

3. Sesen J DP, Scotland SJ, Saland E, Dang V-T, Lemarié A, et al. . Metformin Inhibits Growth of Human Glioblastoma Cells and Enhances Therapeutic Response. PLoS One. 2015;10:e0123721.

4. Warburg O. On the origin of cancer cells. Science. 1956;123:309-14.

5. Bonnet S AS, Allalunis-Turner J, Haromy A, Beaulieu C, Thompson R, et al. . A mitochondria-K+ channel axis is suppressed in cancer and its normalization promotes apoptosis and inhibits cancer growth. Cancer Cell. 2007;11:37-51.

6. McFate T MA, Lu H, Thakar J, Henriques J, Halim ND, et al. Pyruvate dehydrogenase complex activity controls metabolic and malignant phenotype in cancer cells. J Biol Chem. 2008;283:22700-8.

7. Sun RC FM, Dahlstrom JE, Parish CR, Board PG, Blackburn AC. . Reversal of the glycolytic phenotype by dichloroacetate inhibits metastatic breast cancer cell growth in vitro and in vivo. Breast Cancer Res Treat. 2010;120:253-60.

8. Margareto J LO, Larrarte E, Idoate MA, Carrasco A, Lafuente JV. Gene expression profiling of human gliomas reveals differences between GBM and LGA related to energy metabolism and notch signaling pathways. $J$ Mol Neurosci. 2007;32:53-63.

9. Marin-Valencia I YC, Mashimo T, Cho S, Baek H, Yang XL, et al. . Analysis of tumor metabolism reveals mitochondrial glucose oxidation in genetically diverse human glioblastomas in the mouse brain in vivo. Cell Metab. 2012;15:827-37.

10. Hambardzumyan D BG. Glioblastoma: Defining tumour niches. Trends Cancer. 2015;1(4):252-65.

11. Brunner G LK, Wolfe RA, McClure DB, Satob GH. Selective cell culture of brain cells by serum-free, hormonesupplemented media: A comparative morphological study. Developmental Brain Research. 1981;2(4):563-75.

12. Lee J KS, Kotliarov Y, Li A, Su Q, Donin NM, Pastorino S, Purow BW, Christopher N, Zhang W, Park JK, Fine HA. Tumor stem cells derived from glioblastomas cultured in bFGF and EGF more closely mirror the phenotype and genotype of primary tumors than do serum-cultured cell lines. Cancer Cell. 2006;9:391-403.

13. Pollard SM YK, Clarke ID, Danovi D, Stricker S, Russell R, Bayani J, Head R, Lee M, Bernstein M, Squire JA, Smith A, Dirk P. Glioma stem cell lines expanded in adherent culture have tumor-specific phenotypes and are suitable for chemical and genetic screens. Cell Stem Cell. 2009;4:568-80.

14. McCarthy KD dVJ. Preparation of separate astroglial and oligodendroglial cell cultures from rat cerebral tissue. J Cell Biol. 1980;85(3):890-900.

15. Banker GA CW. Rat hippocampal neurons in dispersed cell culture. Brain Research. 1977;126:397-425. 
16. Divakaruni AS PA, Ferrick DA, Murphy AN, Jastroch M. Analysis and Interpretation of Microplate-Based Oxygen Consumption and pH Data. Methods in Enzymology. 2014;547:309-54.

17. Herst PM BM. Cell surface oxygen consumption: a major contributor to cellular oxygen consumption in glycolytic cancer cell lines. Biochim Biophys Acta. 2007;1767(2):170-7.

18. Cataldo AM BR. Cytochemical identification of cerebral glycogen and glucose-6-phosphatase activity under normal and experimental conditions II. Choroid plexus and ependymal epithelia, endothelia and pericytes. J Neurocytol. 1986;15:511-24.

19. Pfeiffer-Guglielmi B FB, Jung G, Hamprecht B. Immunocytochemical localization of glycogen phosphorylase isozymes in rat nervous tissues by using isozyme-specific antibodies. J Neurochem. 2003;85:73-81.

20. Falkowska A GI, Goschorska M, Nowacki P, Chlubek D, Baranowska-Bosiacka I. . Energy Metabolism of the Brain, Including the Cooperation between Astrocytes and Neurons, Especially in the Context of Glycogen Metabolism. Int J Mol Sci. 2015;16:25959-81.

21. Nehlig A PdVA. Glucose and ketone body utilization by the brain of neonatal rats. Prog Neurobiol. 1993;40:163-221.

22. Hao W CC, Tsao CC, Xu J. Oligomycin-induced bioenergetic adaptation in cancer cells with heterogeneous bioenergetic organization. J Biol Chem. 2010;285:12647-54.

23. Comelli M PI, Buso A, Mavelli I. Mitochondrial energy metabolism and signalling in human glioblastoma cell lines with different PTEN gene status. Journal of Bioenergetics and Biomembranes. 2018;50:33-52.

24. Mai WX GL, Daniels VW, Ta L, Tsang JE, Higgins B, Gilmore WB, Bayley NA, Harati MD , Lee JT, Yong WH, Kornblum HI, Bensinger SJ, Mischel PS, Rao PN, Clark PM, Cloughesy TF, Letai A, Nathanson DA.

Cytoplasmic p53 couples oncogene-driven glucose metabolism to apoptosis and is a therapeutic target in glioblastoma. Nature Medicine. 2017;23(11):1342-59.

25. Ishii N TM, Hamou MF, Janzer RC, Meagher-Villemure K, Wiestler OD, Tribolet N, Van Meir EG. Cells with TP53 mutations in low grade astrocytic tumors evolve clonally to malignancy and are an unfavorable prognostic factor. Oncogene. 1999;18:5870-8.

26. Kennedy CR TS, Guan H, Garner JA, Or PMY, Chan AM. Differential sensitivities of glioblastoma cell lines towards metabolic and signaling pathway inhibitions. Cancer Letters. 2013;336:299-306.

27. Hardie DG RF, Hawley SA. . AMPK: a nutrient and energy sensor that maintains energy homeostasis. Nat Rev Mol Cell Biol. 2012;13:251-62.

\section{Tables}

\section{Table 3 - Which cells reflect the metabolic activity of primary GBM cells?}

The metabolic activity of each cell type (primary healthy cells, U87MG, U118MG, U251MG, U373MG, D645, D54, T98G) has been compared with the metabolic activity of primary GBM cells for each metabolic parameter assessed. A tick has been placed in the corresponding box if the cell reflects the metabolic activity of primary GBM cells for the parameter, as determined using absolute values and median of cells compared with primary GBM.

Page $12 / 19$ 


\begin{tabular}{|c|c|c|c|c|c|c|c|c|c|}
\hline & Parameter & Healthy & U87 & U118 & U251 & U373 & D645 & D54 & T98G \\
\hline \multirow{6}{*}{ 胥 } & $\begin{array}{l}\text { Non-mito } \\
\text { respiration }\end{array}$ & $\checkmark$ & & $\checkmark$ & $\checkmark$ & $\checkmark$ & $\checkmark$ & & \\
\hline & $\begin{array}{l}\text { Basal mito } \\
\text { respiration }\end{array}$ & & & $\checkmark$ & $\checkmark$ & $\checkmark$ & & $\checkmark$ & \\
\hline & $\begin{array}{l}\text { ATP-linked } \\
\text { respiration }\end{array}$ & & & & & & $\checkmark$ & & \\
\hline & Proton leak & $\checkmark$ & & $\checkmark$ & $\checkmark$ &  & & 1 & \\
\hline & $\begin{array}{l}\text { Reserve } \\
\text { capacity }\end{array}$ & & $\checkmark$ & & & & & $\checkmark$ & \\
\hline & $\begin{array}{l}\text { Max mito } \\
\text { respiration }\end{array}$ & $\checkmark$ & $\checkmark$ & & $\checkmark$ & $\checkmark$ & & $\checkmark$ & \\
\hline \multirow{3}{*}{ 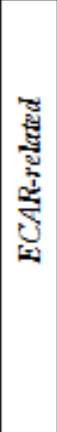 } & $\begin{array}{l}\text { Basal } \\
\text { ECAR }\end{array}$ & $\checkmark$ & & & & & & & $\checkmark$ \\
\hline & $\begin{array}{l}\text { ECAR after } \\
\text { Oligomycin }\end{array}$ & $\checkmark$ & & & $\checkmark$ & & & & $\checkmark$ \\
\hline & $\begin{array}{l}\text { Krebs Cycle } \\
\text { Capacity }\end{array}$ & & & & & & & & $\checkmark$ \\
\hline
\end{tabular}

Figures 


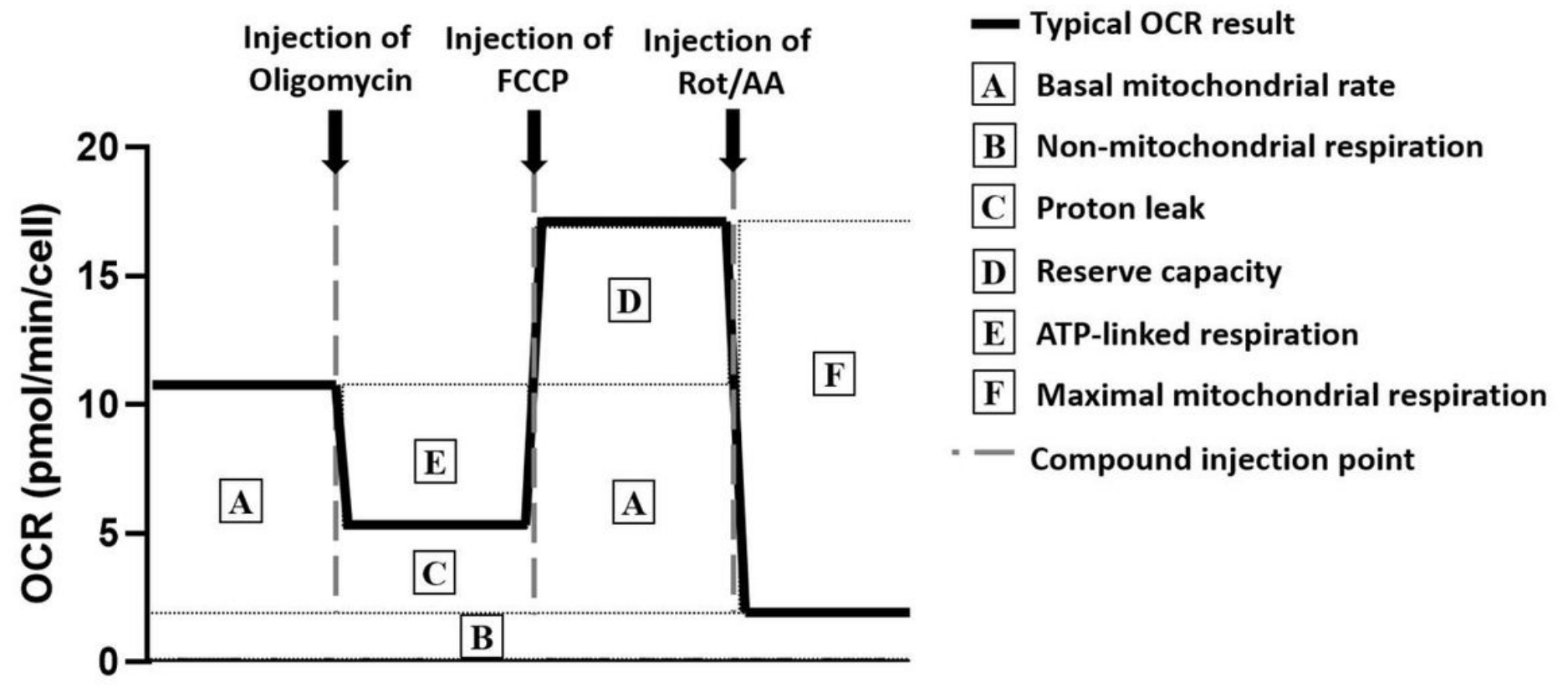

Figure 1

Use of Oxygen Consumption Rate (OCR) profile to calculate mitochondrial and non-mitochondrial related metabolic and oxygen consumption parameters. Different letters have been used to represent the different OCR parameters that have been calculated for these experiments. A represents basal mitochondrial rate; $B$ represents non-mitochondrial respiration; $C$ indicates proton leak; D represents reserve capacity; $E$ represents ATP-linked respiration; $\mathrm{F}$ indicates maximal mitochondrial respiration. A bolded black line shows the typical OCR profile. A dashed grey line indicated compound injection points. 


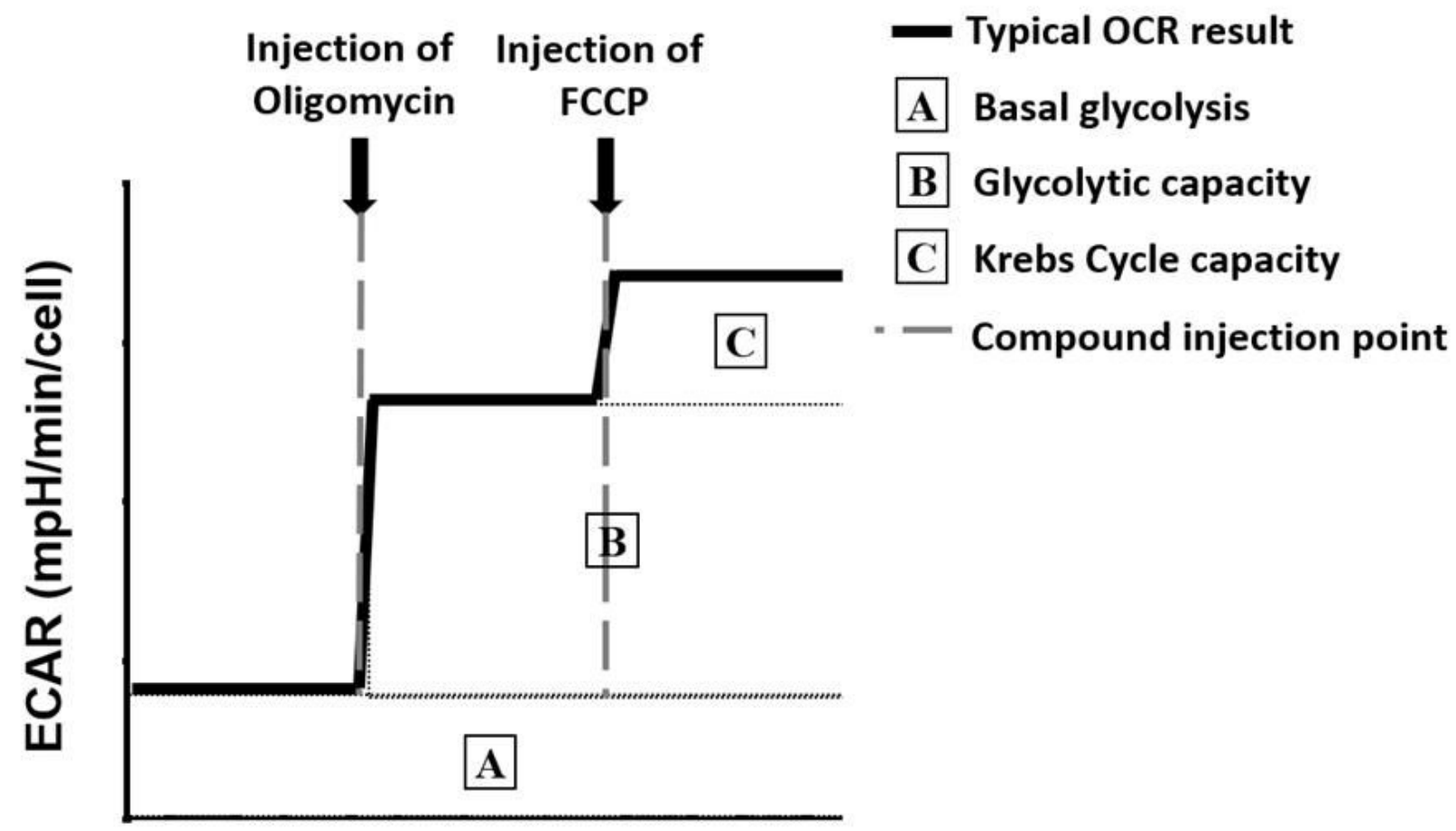

Figure 2

Use of Extracellular Acidification Rate (ECAR) profile to calculate glycolysis-related metabolic parameters.

Different letters have been used to represent the different ECAR parameters that have been calculated for these experiments. A represents basal glycolytic rate; B represents glycolytic capacity; C indicates Krebs Cycle capacity. A bolded black line shows the typical OCR profile. A dashed grey line indicated compound injection points. 


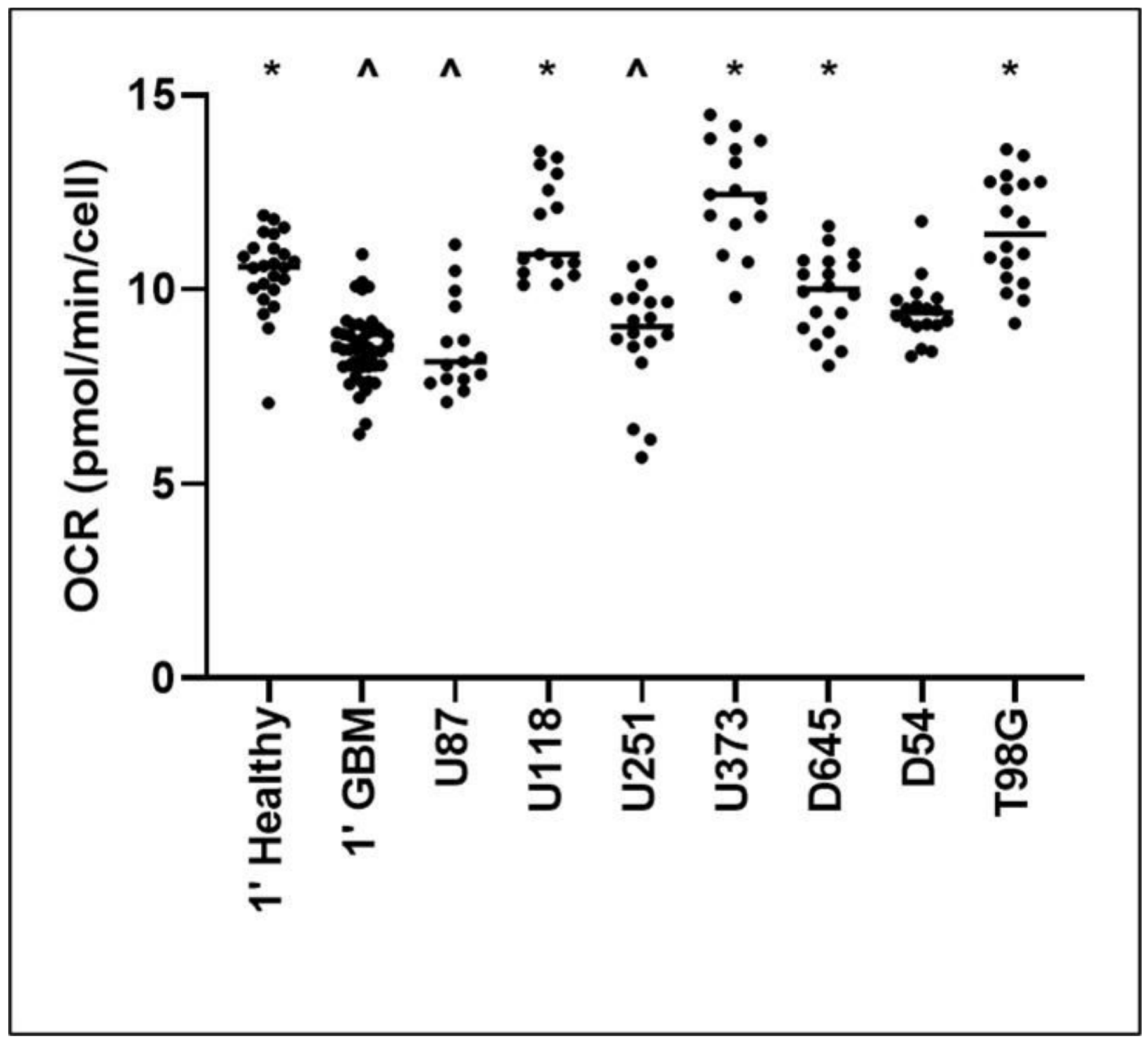

Figure 3

Baseline OCR for primary healthy cells and primary GBM cells, and GBM cell lines Cell populations of primary healthy mixed neural cells and primary GBM cells, and GBM cell lines, were isolated and mitochondrial metabolic activity was measured as changes in OCR. Data presented represent the mean \pm SEM. Biological replicates for cell lines $(n=5)$, primary healthy cells $(n=8)$, and primary GBM tumour cells $(n=13)$; with technical triplicates. * comparison with primary glioblastoma control $\left(1^{\prime} \mathrm{GBM}\right)(\mathrm{p} \leq 0.05) .{ }^{\wedge}$ comparison with primary healthy mixed neural control (1' Healthy) ( $p \leq 0.05)$. 


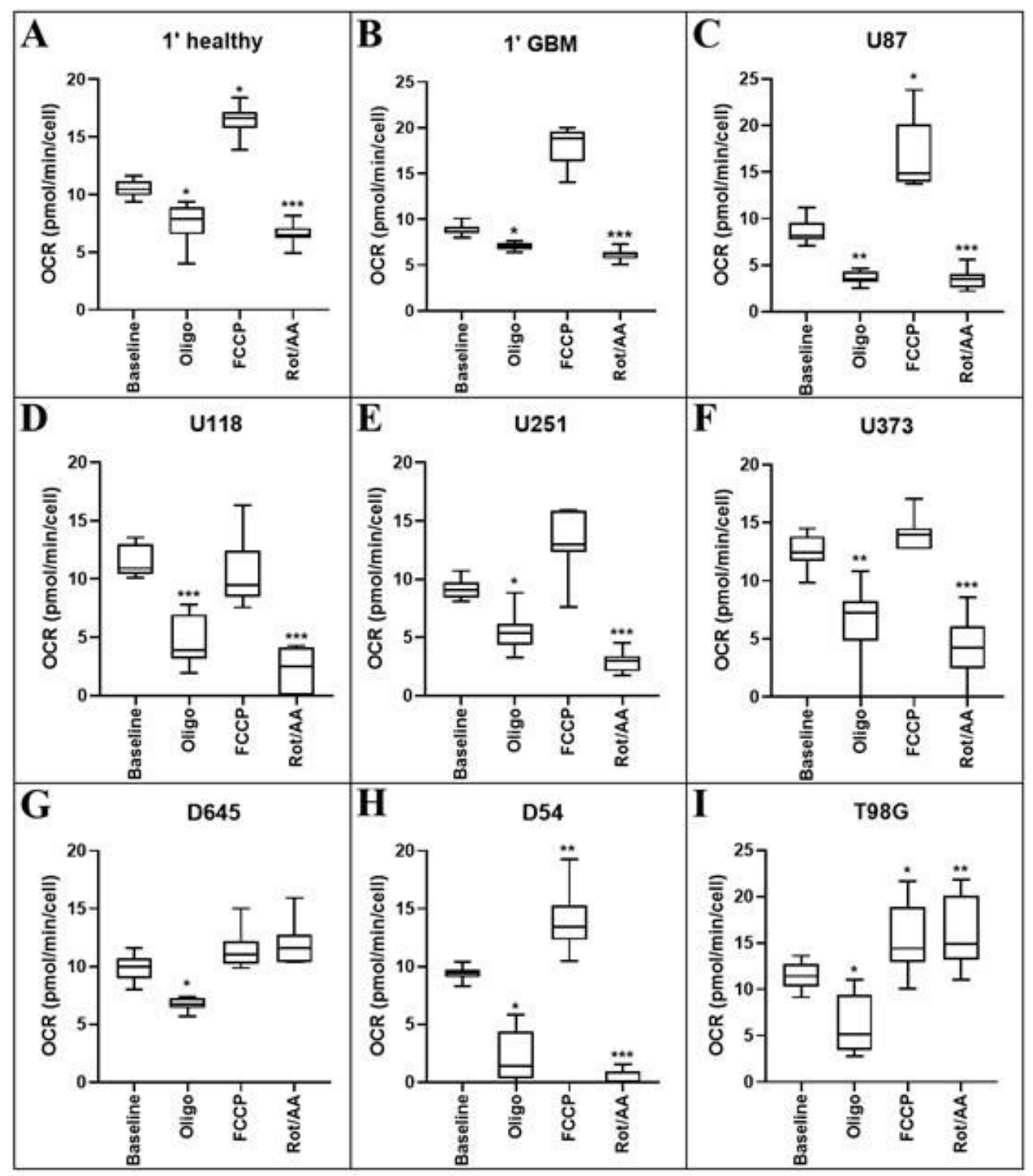

Figure 4

Mitochondrial respiration rate in primary healthy and GBM cells, and GBM cell lines Cell populations of A primary mixed neural cells; B primary GBM cells; C U87MG; D U118MG; E U251MG; F U373MG; G D645; H D54 and; I T98G cells were isolated and mitochondrial metabolic activity was measured as changes in OCR. Data presented represent the mean $+/$ - the standard error of the mean. For all data points in cell lines $n=5$, in primary healthy cells $\mathrm{n}=8$, in primary GBM cells $\mathrm{n}=13$; plated in triplicate. * above error bars show a statistically significant comparison between baseline control and treatment group. * $=p \leq 0.05 ., * *=p \leq 0.01, * \star *=p \leq 0.001$ 


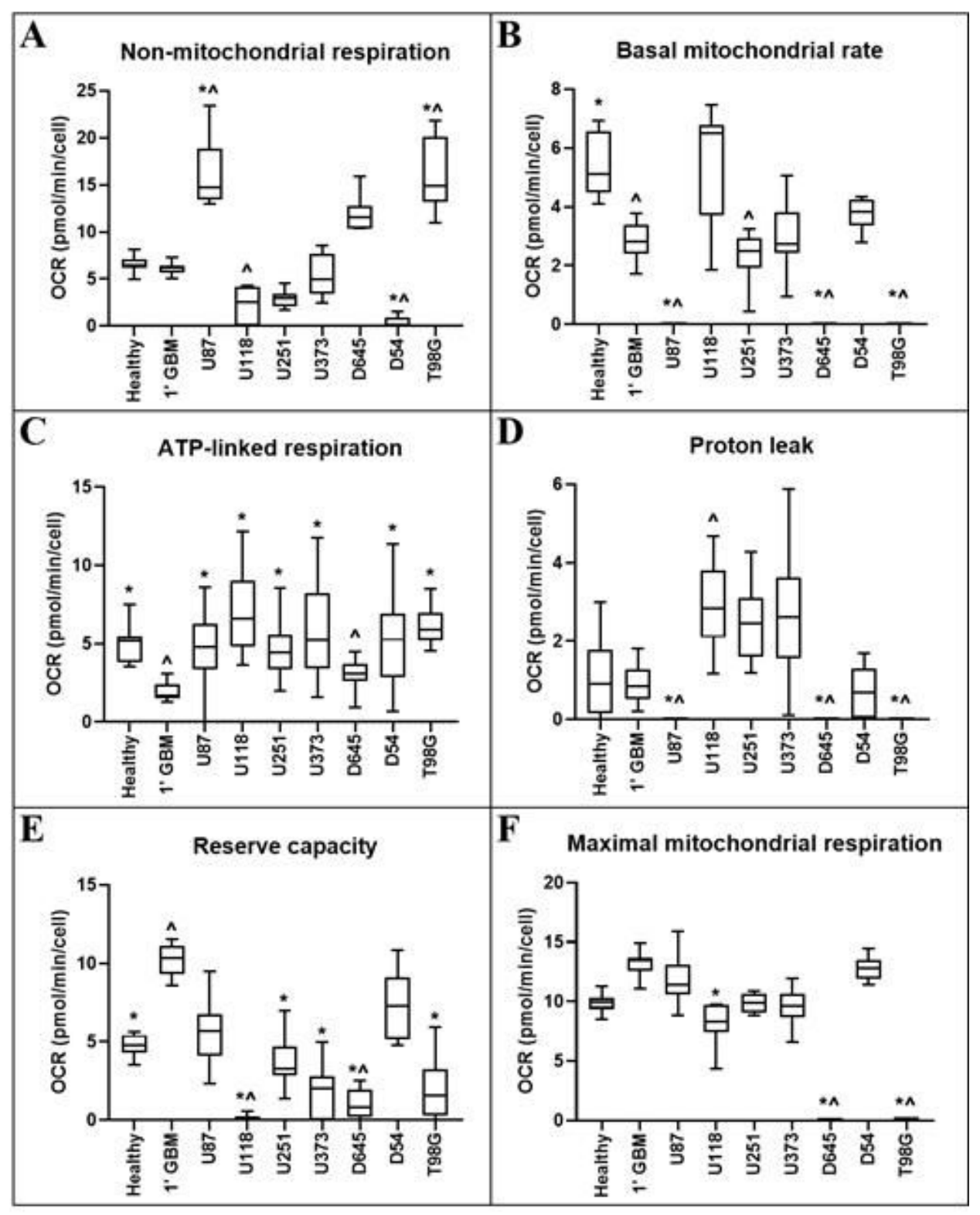

Figure 5

Comparison of OCR-related metabolic parameters of primary neural and GBM cells, and GBM cell lines OCRrelated metabolic parameters A non-mitochondrial respiration; B basal mitochondrial rate; C ATP-linked respiration; D Proton leak; E Reserve capacity and; F Maximal mitochondrial respiration were calculated from measurements obtained using information from Seahorse Bioscience Metabolic Flux Analyser Mito Stress Kit. Data presented represent the mean $+/$ - the standard error of the mean. For all data points in cell lines $n=5$, in primary healthy cells $n=8$, in primary GBM cells $n=13$; plated in triplicate. * above error bars show comparison between primary glioblastoma control ( $\left.1^{\prime} \mathrm{GBM}\right)$ and cell lines reaching statistical significance $(p \leq 0.05) .{ }^{\wedge}$ above error bars show comparison between primary healthy mixed neural control (1' Healthy) and cell lines reaching statistical significance $(p \leq 0.05)$. 


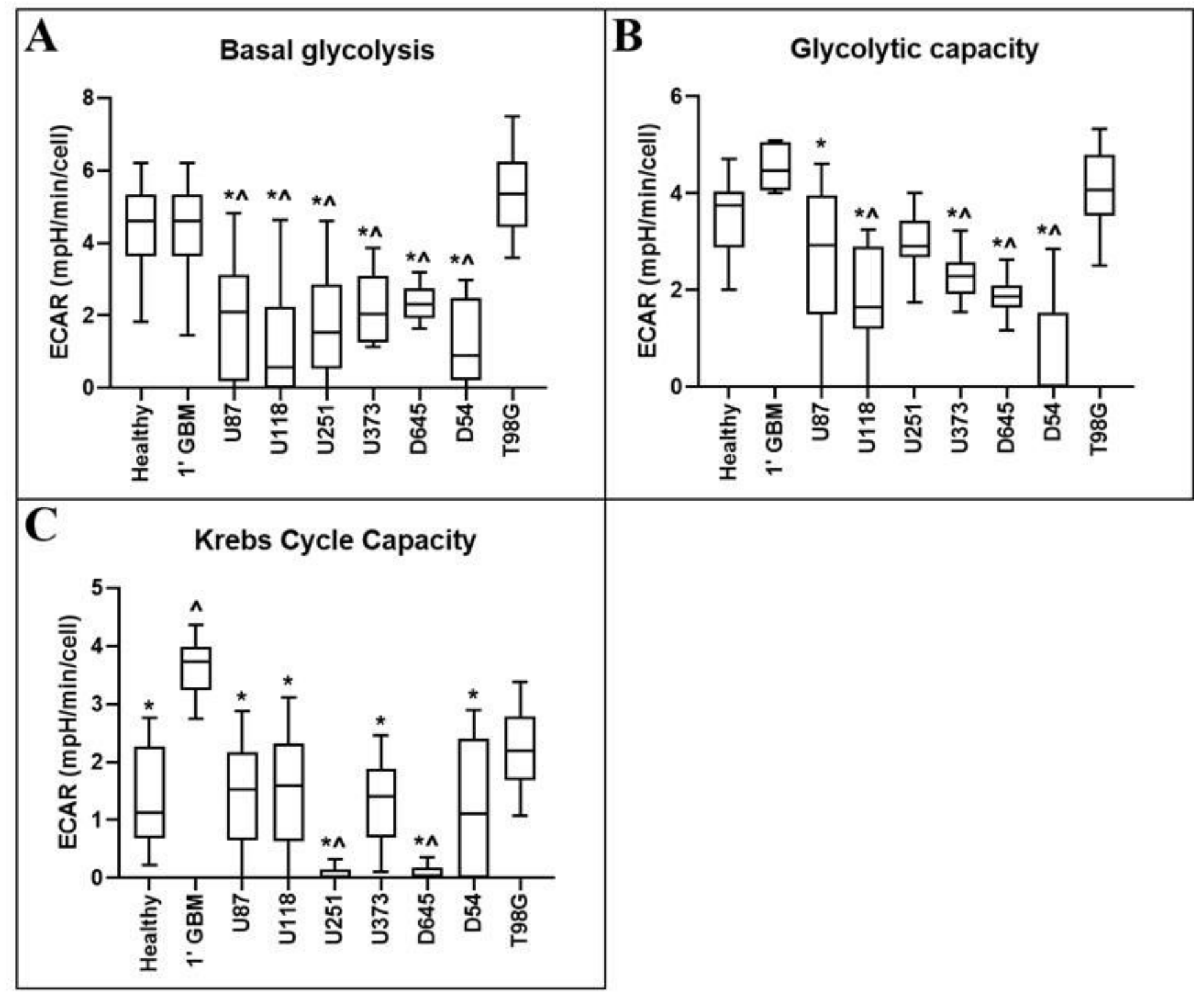

Figure 6

Comparison of ECAR-related metabolic parameters of primary neural and GBM cells, and GBM cell lines ECARrelated metabolic parameters A Basal ECAR; B ECAR after Oligomycin; C Krebs Cycle Capacity were calculated from measurements obtained using information from Seahorse Bioscience Metabolic Flux Analyser Mito Stress Kit. Data presented as Tukey box-and-whisker plot. For all data points in cell lines $n=5$, in primary healthy cells $n=8$, in primary GBM cells $n=13$; plated in triplicate. * above error bars show comparison between primary glioblastoma control (1' GBM) and cell lines reaching statistical significance ( $\leq \leq 0.05) .{ }^{\wedge}$ above error bars show comparison between primary healthy mixed neural control ( 1 ' Healthy) and cell lines reaching statistical significance $(p \leq 0.05)$. 